\title{
InVitro Antioxidant and Free Radical Scavenging Activity of Withania Somnifera Root
}

\author{
${ }^{1,}$ Mohammad Shahriar, ${ }^{2,}$ Md. Ismail Hossain, ${ }^{3,}$ Farzana Anwar Sharmin, \\ ${ }^{4}$ Sadika Akhter, ${ }^{5}$ Md. Aminul Haque and ${ }^{6}$ Mohiuddin Ahmed Bhuiyan

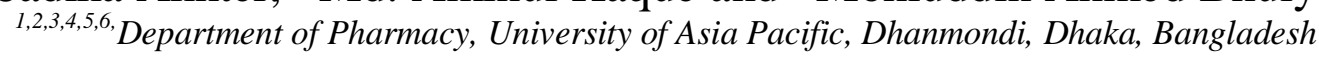

\begin{abstract}
Withania somnifera of the family Solanaceae has been considered as an important herb in the traditional Ayurvedic and in the indigenous medical system in Bangladesh for its use in the prevention of different central nervous system (CNS) disorders, especially in the conditions of stress and neurodegenerative diseases. Five different extracts of Withania somnifera root were scrutinized to unfold the antioxidant and free radical scavenging activity. In the present study, the free radical scavenging potential of five extracts of the root of Withania somnifera was assessed by measuring its capability for scavenging 2, 2-diphenyl-1-picrylhydrazyl (DPPH.) radical, hydrogen peroxide radical, nitric oxide radicals (NO.), as well as its ability in Reducing power capacity assessment, Cupric Reducing Antioxidant Capacity, using appropriate assay systems compared to natural and synthetic antioxidants. Total antioxidant capacity and phenolic, flavonoid contents were determined spectrophotometrically. In-vitro antioxidant activity of the extracts of Withania somnifera was performed and Ethanol and methanol extract of Withania somnifera showed noticeable effect in the DPPH scavenging assay, reducing power capacity, cupric reducing antioxidant capacity and nitric oxide scavenging assay. In case of total phenolic content and total antioxidant capacity methanol and ethanol extract of Withania somnifera showed significant activity. A linear correlation appeared between the total antioxidant capacity and the total phenolics contents of the extracts with good correlation coefficient $\left(R^{2}=0.891\right)$. N-hexane and petroleum ether extract showed least activity in all the measures. Our study demonstrated that the five different extracts of Withania somnifera root showed different level of antioxidant activity and is a potential source of antioxidants and thus could prevent many radical related diseases.
\end{abstract}

Key words: Antioxidant activities, cupric reducing capacity, reducing power, total phenolic and flavonoid content.

\section{INTRODUCTION}

In recent years much attention has been devoted to natural antioxidant and their association with health benefits ${ }^{[1]}$. Nature has been a source of medicinal agents for thousands of years and an impressive number of modern drugs have been isolated from natural resources ${ }^{[2]}$. Plant produces various anti oxidative compounds to counteract reactive oxygen species (ROS) in order to survive ${ }^{[3]}$. ROS, which include free radicals such as superoxide anion radicals $\left(\mathrm{O}_{2^{-}}\right)$, hydroxyl radicals $\left(\mathrm{OH}\right.$.) and non free-radical species such as $\mathrm{H}_{2} \mathrm{O}_{2}$ and singled oxygen, are various forms of activated oxygen. These molecules are exacerbating factors in cellular injury and aging process ${ }^{[4]}$. In foods, ROS can cause lipid per-oxidation, which leads to the deterioration of the food ${ }^{[5]}$. The oxidative deterioration of the lipid-containing food is responsible for the rancid odors and flavors during processing and storage, consequently decreasing the nutritional quality and safety of foods, due to the formation of secondary, potentially toxic compounds. The addition of antioxidant is a method for increasing the shelf life of foods ${ }^{[6]}$. Medicinal plants possess secondary metabolites like alkaloids, glycosides, steroids and flavonoids which are the important sources of drugs ${ }^{[7]}$. Plant phenolics are commonly found in both edible and non-edible plants, and have been reported to have multiple biological effects, including antioxidant activity. The antioxidant activity of phenolics is mainly due to their redox properties, which allow them to act as reducing agents, hydrogen donators, and singlet oxygen quenchers. In addition, they have a metal chelation potential ${ }^{[8]}$. The phenolic compounds are increasingly of interest in the food industry because they retard oxidative degradation of lipids and thereby improve the quality and nutritional value of food ${ }^{[9]}$. The importance of natural phenolic compounds from plants materials is also raising interest among scientists, food manufacturers, and consumers due to functional food with specific health effects ${ }^{[10]}$.

Withania somnifera is a small and erect evergreen woody under shrub that grows up to a height of 1-m tall and belongs to the family of solanaceae locally known as Ashwagandha. This plant is capable of growing wildly not only in all the drier parts of the subtropical Bangladesh i.e. in Nator, Savar, and North-western parts of Bangladesh but also in India, Congo, South Africa, Egypt, Morocco, Jordan, Pakistan and Afghanistan. The 
roots are the main portions of the whole plant as they possess wide number of the therapeutic agents. The crude aqueous extract of the plant contains the phenolics and flavonoids which are said to be the potent antioxidants [11]. Ashwagandha is found to be a major ingredient of various adaptogenic and anti-stress tonics ${ }^{[12]}$. A methanolic extract of the various parts of Withania somnifera had showed a potent anti-inflammatory activity. Withania somnifera is found to be a unique plant where a wider range of biological activities has been demonstrated including antagonism with several inflammatory factors and the immune modulation. Several studies had been conducted to evaluate the correlation between phenolic compounds and antioxidant activity. The antioxidative properties of some vegetables and fruits are partly due to the low molecular weight phenolic compounds, which are known to be potent as antioxidants ${ }^{[13]}$. Recently, there are numerous methods that have been developed to evaluate antioxidant activities of compounds and of complex mixtures such as plant extracts ${ }^{[14]}$. Despite the existence of these various methods, just one procedure cannot identify all possible mechanisms characterizing an antioxidant activity ${ }^{[15]}$. Therefore, the aim of this study is to evaluate the anti-oxidative activity of Withania somnifera root using several different methods, and to evaluate the relationship between the anti-oxidative activity and total phenolic content of the plants.

\section{MATERIALS AND METHODS}

\subsection{Chemicals}

diphenyl-2-picrylhydrazyl (DPPH), Butylated hydroxy anisole (BHA), was obtained from Sigma Aldrich. Other chemicals, Sodium carbonate, Sodium phosphate, Potassium acetate, Methanol, Ethanol, Petroleum ether, Butylated hydroxytoluene (BHT), Gallic acid, Neocaproin, Potassium dihydrogen phosphate, Acetic acid (glacial), Cupric chloride, Concentrated $\mathrm{H}_{2} \mathrm{SO}_{4}(96 \%), \mathrm{H}_{2} \mathrm{O}_{2}(30 \%$, v/v) were obtained from (Merck KGaA, Darmstadt, Germany). Sodium nitroprusside, Sulphanilamide, Ascorbic acid, Ferric chloride, n-Hexane, Naphthyl ethylenediamine dihydrochloride, Folin - ciocalteu reagent from Loba Chemie Pvt. Ltd, India. Trichloro Acetic acid, Sodium chloride crystal, Sodium hydroxide pellets, Chloroform, Ammonium acetate from Merck Specialities Private Limited, India. Potassium ferricyanide from UNI-CHEM, China. Ammonium Molybdate from BDH Chemicals Ltd, England. Aluminium chloride from UNI-CHEM, China. Quercetin from Aldrich Chemistry, Switzerland.

\subsection{Extraction Procedure}

Plant sample of Withania somnifera was collected from suburb of Dhaka, Bangladesh. After complete cleaning and ringing with water roots were sun dried for fifteen days and then dried in an oven at $40^{\circ} \mathrm{C}$ for three days. The dried roots were then grinded in coarse powder using high capacity grinding machine. The powdered plant material $(20 \mathrm{gm})$ was successively extracted in a soxhlet extractor at elevated temperature using $200 \mathrm{ml}$ of distilled petroleum ether $\left(40-60^{\circ} \mathrm{C}\right)$ which was followed by n-hexane, ethanol, chloroform and methanol. All extracts were filtered individually through filter paper and poured on petri dishes to evaporate the liquid solvents from the extract to get dry extracts. After drying, crude extracts were weighed and stored in stock vials and kept in refrigerator $\left(0-4^{\circ} \mathrm{C}\right)$ for farther use.

\subsection{Determination of Total Phenolic Content}

Total phenolic contents in the extracts were determined by the Folin-Ciocalteu reagent method described by Demiray et al. ${ }^{[16]} .1 \mathrm{ml}$ of the plant extract/standard of different concentration solution was mixed with $5 \mathrm{ml}$ folin-ciocalteu reagent (previously diluted with water 1:10 v/v) and $4 \mathrm{ml}(7.5 \%$ sodium carbonate) of sodium carbonate. The tubes were vortexed for few seconds and allowed to stand for $30 \mathrm{~min}$ at $20^{\circ} \mathrm{C}$ for color development. Absorbance of samples and standard were measured at $765 \mathrm{~nm}$ using spectrophotometer against blank. A typical blank solution contained the solvent used to dissolve the plant extract. The total content of phenolic compounds in plant extracts in gallic acid equivalents (GAE) was calculated using the following equation:

$$
\mathrm{C}=(\mathrm{c} \times \mathrm{V}) / \mathrm{m}
$$

Where; $\mathrm{C}=$ total content of phenolic compounds, $\mathrm{mg} / \mathrm{gm}$ plant extract, in GAE, $\mathrm{c}=$ the concentration of gallic acid established from the calibration curve $(\mathrm{mg} / \mathrm{ml}), \mathrm{V}=$ the volume of extract in $\mathrm{ml}, \mathrm{m}=$ the weight of crude plant extract in gm.

\subsection{Determination of Total Flavonoids Content}

Aluminum chloride colorimetric method was used for flavonoids determination ${ }^{[17]} .1 \mathrm{ml}$ of the plant extracts/standard of different concentration solution was mixed with $3 \mathrm{ml}$ of methanol, $0.2 \mathrm{ml}$ of aluminum chloride, $0.2 \mathrm{ml}$ of $1 \mathrm{M}$ potassium acetate and $5.6 \mathrm{ml}$ of distilled water. It remained at room temperature for 30 min then absorbance of the reaction mixture was measured at $415 \mathrm{~nm}$ with spectrophotometer against blank. Methanol served as blank. The total content of flavonoid compounds in plant methanol extracts in quercetin equivalents was calculated by the following equation: 


$$
\mathrm{C}=(\mathrm{c} \times \mathrm{V}) / \mathrm{m}
$$

Where; $\mathrm{C}=$ total content of flavonoid compounds, $\mathrm{mg} / \mathrm{gm}$ plant extract, in quercetin equivalent, $\mathrm{c}=$ the concentration of quercetin established from the calibration curve in $\mathrm{mg} / \mathrm{ml}, \mathrm{V}=$ the volume of extract in $\mathrm{ml}$ and $\mathrm{m}=$ the weight of crude plant extract in gm.

\subsection{Determination of Total Antioxidant Capacity}

The total antioxidant capacity was evaluated by the phosphomolybdenum method ${ }^{[18]} .0 .3 \mathrm{ml}$ of extract and sub-fraction in ethanol, ascorbic acid used as standard $(5-200 \mu \mathrm{g} / \mathrm{ml})$ and blank (ethanol) were combined with $3 \mathrm{ml}$ of reagent mixture separately and incubated at $95^{\circ} \mathrm{C}$ for 90 minutes. After cooling to room temperature, the absorbance of each sample was measured at $695 \mathrm{~nm}$ against the blank. The antioxidant activity is expressed as the number of equivalents of ascorbic acid and was calculated by the following equation: $A=(c \times V) / m$

Where, $\mathrm{A}=$ total content of antioxidant compounds, $\mathrm{mg} / \mathrm{gm}$ plant extract, in ascorbic acid equivalent $\mathrm{c}=$ the concentration of ascorbic acid established from the calibration curve, $\mathrm{mg} / \mathrm{ml}, \mathrm{V}=$ the volume of extract in $\mathrm{ml}, \mathrm{m}$ $=$ the weight of crude plant extract, gm.

\subsection{DPPH Free Radical Scavenging Assay}

The free radical scavenging capacity of the extracts was determined using DPPH ${ }^{[19]}$. Freshly prepared DPPH solution was taken in test tubes and extracts were added followed by serial dilutions $(15.625 \mu \mathrm{g} / \mathrm{ml}$ to 250 $\mu \mathrm{g} / \mathrm{ml}$ ) to every test tube so that the final volume was $5 \mathrm{ml}$ and after $30 \mathrm{~min}$, the absorbance was read at $517 \mathrm{~nm}$ using a spectrophotometer. Ascorbic acid and Butylated hydroxy toluene (BHT) was used as standard. Control sample was prepared containing the same volume without any extract and standard and the absorbance was read at $517 \mathrm{~nm}$ using a spectrophotometer. Methanol was served as blank.

\subsection{Reducing Power Capacity Assessment}

Assay of reducing power was carried out by potassium ferricyanide method ${ }^{[20]} .1 \mathrm{ml}$ of extract and its sub-fractions (final concentration $5-200 \mu \mathrm{g} / \mathrm{ml}$ ) were mixed with $2.5 \mathrm{ml}$ phosphate buffer $(0.2 \mathrm{M}$, pH 6.6) and $2.5 \mathrm{ml}$ potassium ferricyanide. The mixture was then incubated at $50^{\circ} \mathrm{C}$ for 20 minutes. To this mixture $2.5 \mathrm{ml}$ of trichloroacetic acid was added, which was then centrifuged at $3000 \mathrm{rpm}$ for 30 minutes. Finally, $2.5 \mathrm{ml}$ of the supernatant solution was collected and mixed with $2.5 \mathrm{ml}$ of distilled water and $0.5 \mathrm{ml}$ ferric chloride and absorbance was measured at $700 \mathrm{~nm}$. Ascorbic acid and Butylated hydroxy toluene (BHT) was used as standard and phosphate buffer as blank solution.

\subsection{Scavenging of Hydrogen Peroxide}

Scavenging activity of extract and its sub-fractions were evaluated by hydrogen peroxide ${ }^{[21]} .1 \mathrm{ml}$ of various concentrations of the extract, sub-fractions and standards in ethanol was added to 2 ml of hydrogen peroxide solution in phosphate buffered saline (PBS, $\mathrm{pH}$ 7.4). Then finally the absorbance was measured at 230 nm after 10 minutes. Ascorbic acid and Butylated hydroxy toluene (BHT) was used as standard. Control sample was prepared containing the same volume without any extract and standard and the absorbance was read at 230 nm using a spectrophotometer.

\subsection{Nitric Oxide Scavenging Capacity Assay}

Nitric oxide scavenging assay was carried by using sodium nitroprusside ${ }^{[22]}$. This can be determined by the use of the Griess Illosvoy reaction. $2 \mathrm{ml}$ of $10 \mathrm{mM}$ sodium nitroprusside in $0.5 \mathrm{ml}$ phosphate buffer saline ( $\mathrm{pH} 7.4$ ) was mixed with $0.5 \mathrm{ml}$ of extract/sub-fraction at various concentrations and the mixture was incubated at $25^{\circ} \mathrm{C}$ for 150 minutes. From the incubated mixture $0.5 \mathrm{ml}$ was taken out and added into $1.0 \mathrm{ml}$ sulphanilamide solution $(0.33 \%$ in $20 \%$ glacial acetic acid) and further incubated at room temperature for 5 minutes. Finally, 1.0 $\mathrm{ml}$ naphthyl ethylenediamine dihydrochloride $(0.1 \% \mathrm{w} / \mathrm{v})$ was mixed and maintained at room temperature for 30 minutes. The absorbance was measured at $546 \mathrm{~nm}$. A typical blank/control solution contained the same solution mixture without plant extract or standard. The absorbance of the blank/control solution was measured at 546 $\mathrm{nm}$. The percentage inhibition was calculated according to the following equation:

$\%$ inhibition $=\left(1-\frac{A_{1}}{A_{0}}\right) \times 100$

Where, $\mathrm{A}_{1}=$ Absorbance of the extract or standard, $\mathrm{A}_{0}=$ Absorbance of the control 


\subsection{Cupric Reducing Antioxidant Capacity (CUPRAC)}

The assay was conducted as described previously Resat et al. ${ }^{[23]}$. To $0.5 \mathrm{ml}$ of plant extract or standard of different concentrations solution, $1 \mathrm{ml}$ of copper (II) chloride solution ( $0.01 \mathrm{M}$ prepared from $\left.\mathrm{CuCl}_{2} .2 \mathrm{H}_{2} \mathrm{O}\right), 1$ $\mathrm{ml}$ of ammonium acetate buffer at $\mathrm{pH} 7.0$ and $1 \mathrm{ml}$ of neocaproin solution $(0.0075 \mathrm{M})$ were mixed. The final volume of the mixture was adjusted to $4.1 \mathrm{ml}$ by adding $0.6 \mathrm{ml}$ of distilled water and the total mixture was incubated for 1 hour at room temperature. Then the absorbance of the solution was measured at $450 \mathrm{~nm}$ using a spectrophotometer against blank. Ascorbic acid, BHT and BHA was used as a standard.

\subsection{Total Phenolic Content}

\section{RESULTS AND DISCUSSION}

Total phenolic content of the different extracts of Withania somnifera root was determined by using the Folin-Ciocalteu reagent and were expressed as gallic acid equivalents (GAE) per gram of plant extract. The total phenolic contents of the test fractions were calculated using the standard curve of gallic acid $(y=0.013 x+$ 0.037; $\mathrm{R}^{2}=0.994$ ) (Figure 1). Chloroform extract of Withania somnifera was found to contain the highest amount of phenols (Phenol contents of the extracts were found to decrease in the following order: Chloroform extract $>$ Petroleum ether extract $>$ Methanol extract $>$ Ethanol extract $>n$-hexane extract (Table 1). The results strongly suggest that phenolics are important components of the tested plant extracts. Literature reveals that antioxidant activity of plant extract is mainly due to presence of phenolic compounds, which may exerts antioxidant effects as free radical scavengers, as hydrogen donating sources or as singlet oxygen quenchers and metal ion chelators.

\subsection{Total Flavonoid Content}

Aluminium chloride colorimetric method was used to determine the total flavonoid contents of the different extracts of Withania somnifera. Total flavonoid contents was calculated using the standard curve of quercetin $\left(\mathrm{y}=0.014 \mathrm{x}-0.062 ; \mathrm{R}^{2}=0.994\right)$ (Figure 2$)$ and was expressed as quercetin equivalents $(\mathrm{QE})$ per gram of the plant extract. Chloroform extract of Withania somnifera was found to contain the highest amount of flavonoid (Table 2). Flavonoid contents of the extracts were found to decrease in the following order: Chloroform extract > Petroleum ether extract > Methanol extract > Ethanol extract >n-hexane extract.Flavonoids play an important role in antioxidant system in plants. The antioxidative properties of flavonoids are due to several different mechanisms, such as scavenging of free radicals, chelation of metal ions, such as iron and copper and inhibition of enzymes responsible for free radical generation ${ }^{[24]}$. Depending on their structure, flavonoids are able to scavenge practically all known ROS. According to our study, the high contents of flavonoids in Withania somnifera can explain its high radical scavenging activity.

\subsection{Total Antioxidant Capacity}

Total antioxidant capacity of the different extracts of Withania somnifera was evaluated by the phosphomolybdenum method and was expressed as ascorbic acid equivalents (AAE) per gram of plant extract. Total antioxidant capacity of the test samples was calculated using the standard curve of ascorbic acid $(\mathrm{y}=$ $0.002 x+0.001 ; R^{2}=0.997$ ) (Figure 3). Chloroform extract of Withania somnifera was found to possess the highest total antioxidant capacity (Table 3). Total antioxidant capacity of the extracts was found to decrease in the following order: Chloroform extract $>$ Petroleum ether extract $>$ Methanol extract $>$ Ethanol extract $>n$ hexane extract. According to recent reports, a highly positive relationship between total phenols and antioxidant activity appears to be the trend in many plant species ${ }^{[25]}$. The statement has been justified in the current study where the chloroform extract of Withania somnifera showed maximum total antioxidant capacity (in term of ascorbic acid equivalent) (Table 3) with maximum phenol content (Table 1).

\section{4 .Relationship between the Total Antioxidant Capacity and the Total Phenolics Content}

The extent of antioxidant capacity of extract of Withania somnifera was correlated with their total phenolics content. A linear correlation appeared between the total antioxidant capacity and the total phenolics content of the extract and fractions with good correlation coefficient $\left(R^{2}=0.820\right)$. The results suggested that the phenolic compounds contributed significantly to the antioxidant capacity of the Withania somnifera extracts.

\subsection{DPPH free radical scavenging assay}

The free radical scavenging activity of different extracts of Withania somnifera root was studied by its ability to reduce the DPPH, a stable free radical and any molecule that can donate an electron or hydrogen to $\mathrm{DPPH}$, can react with it and thereby bleach the DPPH absorption. DPPH is a purple color dye having absorption 
maxima of $517 \mathrm{~nm}$ and upon reaction with a hydrogen donor the purple color fades or disappears due to conversion of it to 2, 2-diphenyl-1-picryl hydrazine resulting in decrease in absorbance. Chloroform, pet-ether and methanol extracts showed maximum activity of $75.37 \%, 63.61 \%$ and $54.16 \%$ respectively at $250 \mu \mathrm{g} / \mathrm{ml}$, where as ascorbic acid and BHT at the same concentration exhibited $96.66 \%$ and $92.59 \%$ inhibition respectively. Five extracts exhibited considerable DPPH free radical scavenging activity as indicated by their $\mathrm{IC}_{50}$ values and this has been showed in (Table 2 and Figure 1 ). $\mathrm{IC}_{50}$ Indicate the potency of scavenging activity. Standard ascorbic acid and BHT were found to have an $\mathrm{IC}_{50}$ of $5.698 \mu \mathrm{g} / \mathrm{ml}$ and $8.816 \mu \mathrm{g} / \mathrm{ml}$. In comparison to standard ascorbic acid and BHT, chloroform, pet-ether and methanol extract of Withania somnifera root showed IC $_{50}$ of $87.414,144.998$ and 267.818 respectively. Ethanol and n-hexane fraction is seen to have the least free radical scavenging activity.

\subsection{Reducing Power Capacity Assessment}

Reducing power of the fractions was assessed using ferric to ferrous reducing activity as determined spectrophotometrically from the formation of Perl's Prussian blue colour complex ${ }^{[20]}$. Reducing power of different extracts of Withania somnifera was compared with ascorbic acid and BHT (Figure 6). Among the extract the chloroform extract exhibited the most reducing power. This result indicates that the extracts may consist of polyphenolic compounds that usually show great reducing power. This has been justified by chloroform extract being the most reducing agent with highest phenolic content (Table 1).

\subsection{Scavenging of Hydrogen Peroxide}

Hydrogen peroxide, although not a radical species play a role to contribute oxidative stress. The generation of even low levels of $\mathrm{H}_{2} \mathrm{O}_{2}$ in biological systems may be important. Naturally-occurring iron complexes inside the cell believed to react with $\mathrm{H}_{2} \mathrm{O}_{2}$ in vivo to generate highly reactive hydroxyl radicals and this may be the origin of many of its toxic effects ${ }^{[26]}$. Scavenging of hydrogen peroxide of different extracts of Withania somnifera root is presented in figure 7. Among five extracts Chloroform, pet-ether and methanol extract showed good activity taking chloroform in the top position in depleting $\mathrm{H}_{2} \mathrm{O}_{2}$ with an $\mathrm{IC}_{50}$ value of $89.188,162.643$ and $172.661 \mu \mathrm{g} / \mathrm{ml}$ respectively (Table 5).

The percentage of $\mathrm{H}_{2} \mathrm{O}_{2}$ scavenging activity of Chloroform extract was found to be $59.45 \%$ which is highest among five extract at $200 \mu \mathrm{g} / \mathrm{ml}$ compared to antioxidant activity of standard ascorbic acid and BHT was 82.88 $\%$ and $81.81 \%$, respectively at the same concentration. Pet-ether and methanol extract also showed significant activity with a scavenging value of $51.65 \%$ and $54.38 \%$ respectively.

\subsection{Nitric Oxide Scavenging Assay}

Nitric oxide is a very unstable species and reacting with oxygen molecule produce stable nitrate and nitrite which can be estimated by using Griess reagent. In the presence of a scavenging test compound, the amount of nitrous acid will decrease which can be measured at $546 \mathrm{~nm}$. Chloroform extract of Withania somnifera root has potent nitric oxide scavenging activity $\left(\mathrm{IC}_{50}\right.$ value $\left.92.207 \mu \mathrm{g} / \mathrm{ml}\right)$ and $\mathrm{n}$-hexane fraction has showed the least nitric oxide scavenging activity $\left(\mathrm{IC}_{50}\right.$ value $847.026 \mu \mathrm{g} / \mathrm{ml}$ ) (Table 6 ). The scavenging of NO by the extracts was increased in dose dependent manner. Figure 8 illustrates a significant decrease in the NO radical due to the scavenging ability of extracts and ascorbic acid. The chloroform and Pet-ether extract showed maximum activity of $53.56 \%$ and $42.93 \%$ respectively at $100 \mu \mathrm{g} / \mathrm{ml}$, where as ascorbic acid and BHT at the same concentration exhibited $76.65 \%$ and $80.84 \%$ inhibition respectively.

\subsection{Cupric Reducing Antioxidant Capacity (CUPRAC)}

Reduction of $\mathrm{Cu}^{2+}$ ion to $\mathrm{Cu}^{+}$was found to rise with increasing concentrations of the different extracts. The standard ascorbic acid, BHA and BHT showed highest reducing capacity. Among the extracts the chloroform extract of Withania somnifera showed maximum reducing capacity that is comparable to ascorbic acid, BHA and BHT (Figure 9). This method is based on the principle of increase in the absorbance of the reaction mixtures. Increase in the absorbance indicates increase in the antioxidant activity hence indicates the reducing power of the samples ${ }^{[27]}$. Reducing power is associated with antioxidant activity and may serve as a significant reflection of the antioxidant activity ${ }^{[25]}$. Compounds with reducing power indicate that they are electron donors and can reduce the oxidized intermediates of lipid per-oxidation processes, so that they can act as primary and secondary antioxidants ${ }^{[28]}$. 


\section{CONCLUSION}

All the conducted experiments in the present study are based on crude extract and are considered to be preliminary and more sophisticate research is necessary to reach a concrete conclusion about the findings of the present study. To sum up, these findings together demonstrate that Withania somnifera is an excellent plant candidate for further investigation of individual phenolic compounds, their in vivo antioxidant activity and the different antioxidant mechanisms and also appears to be a most promising candidate from which specific antioxidant bioactive products could be developed. Therefore, in depth extensive study should be an urgency to sort out bioactive compounds.

\section{REFERENCES}

[1] A Arnous, D.P. Makris, and P. Kefalas, Effect of principal polyphenolic components in relation to antioxidant characteristics of aged red wines, Journal of Agricultural and Food Chemistry, 49(12), 2001, 5736-5742.

[2] K Gautam, and P. Kumar, Extraction and pharmacological evaluation of some extracts of Vitex negundo Linn, International Journal of Pharmacy and Pharmaceutical Sciences, 4(2), 2012, 132-137.

[3] F. Lu, and L.Y. Foo, Toxicological aspects of food antioxidants (New York: Marcel Dekker; 1995).

[4] I Gülçin, M. Oktay, E. Kıreçci, and O.I. Küfrevioglu, Screening of antioxidant and antimicrobial activities of anise (Pimpella anisum L.) seed extracts, Food Chemistry, 83(3), 2003, 371-382.

[5] NJ Miller, and C.A. Rice-Evans. The relative contributions of ascorbic acid and phenolic antioxidants to the total antioxidants activity of orange and apple fruit juices and blackcurrant drink, Food Chemistry, 60(3), 1997, 331-337.

[6] NC Cook, and S. Samman, Flavonoids-chemistry, metabolism, cardioprotective effects and dietary sources, The Journal of Nutritional Biochemistry, 7(2), 1996, 66-76.

[7] A Kathirvel, and V. Sujatha, Phytochemical analysis and antioxidant activity of Barringtonia acutangula (L.) gaertn Leaves, International Journal of Pharmacy and Pharmaceutical Sciences, 4(2), 2012, 277-281.

[8] CA Rice-Evans, N.J. Miller, P.G. Bolwell, P.M. Bramley, and J.B. Pridham, The Relative Antioxidant Activities of PlantDerived Polyphenolic Flavonoids, Free Radical Research, 22(4), 1995, 375-383.

[9] MP Kähkönen, A.I. Hopia, H.J. Vuorela, J.P. Rauha, K. Pihlaja, and T.S. Kujala, Antioxidant activity of plant extracts containing phenolic compounds, Journal of Agricultural and Food Chemistry, 47(10), 1999, 3954-3962.

[10] J. Löliger, The use of antioxidants in food: Free Radicals and Food Additives (London: Taylor and Francis; 1991).

[11] V Mehrotra, S. Mehrotra, V. Kirar, S. Radhey, K. Misra, A.K. Srivastava, and S.P. Nandi, Antioxidant and antimicrobial activities of aqueous extract of Withania somnifera against methicillin-resistant Staphylococcus aureus, Journal of Microbiology and Biotechnology Research, 1(1), 2011, 40-45.

[12] M Bhatnagar, C.P. Jain, and S.S. Sisodia, Anti-ulcer activity of Withania somnifera in stress plus pyloric ligation induced gastric ulcer in rats. Journal of Cell and Tissue Research, 5(1), 2005, 287-292.

[13] H Wang, M.G. Nair, G.M. Strasburg, A.M. Booren, J.I. Gray, Antioxidant polyphenols from tart cherries (Prunus cerasus), Journal of Agricultural and Food Chemistry, 47(3), 1999, 840-844.

[14] M Antolovich, P.D. Prenzler, E. Patsalides, S. McDonald, and K. Robards, Methods for testing antioxidant activity, The Analyst, 127(1), 2002, 183-198.

[15] EN Frankel, and A.S. Meyer, The problems of using one-dimensional methods to evaluate multifunctional food and biological antioxidants, Journal of the Science of Food and Agriculture, 80(13), 2000, 1925-1941.

[16] S Demiray, M.E. Pintado, and P.M.L. Castro, "Evaluation of Phenolic Profiles and Antioxidant Activities of Turkish Medicinal Plants: Tilia argentea, Crataegi folium Leaves and Polygonum bistorta Roots," World Academy of Science, Engineering and Technology, 54, 2009, 312-317.

[17] SY Wang and H. Jiao, Correlation of antioxidant capacities to oxygen radical scavenging enzyme activities in blackberry, Journal of Agricultural and Food Chemistry, 48(11), 2000, 5672-5676.

[18] P Prieto, M. Pineda and M. Aguilar, Spectrophotometric Quantitation of Antioxidant Capacity through the Formation of a Phosphomolybdenum Complex: Specific Application to the Determination of Vitamin E, Analytical Biochemistry, 269(2), 1999, 337-341.

[19] A Braca, N.D. Tommasi, L.D. Bari, C. Pizza, M. Politi, and I. Morelli, Antioxidant principles from Bauhinia tarapotensis, Journal of Natural Products, 64(7), 2001, 892-895.

[20] A Yildirim, A. Mavi, and A.A. Kara, Determination of Antioxidant and Antimicrobial Activities of Rumex crispus L. Extracts, Journal of Agricultural and Food Chemistry, 49(8), 2001, 4083-4089.

[21] GK Jayaprakasha, R.P. Singh, and K.K. Sakariah, Antioxidant activity of grape seed (Vitis vinifera) extracts on peroxidation models in vitro, Food Chemistry, 73(3), 2001, 285-290.

[22] Sreejayan and M.N.A. Rao, Nitric Oxide Scavenging by Curcuminoids, Journal of Pharmacy and Pharmacology, 49(1), 1997, $105-107$.

[23] R Apak, K. Güçlü, M. Özyürek, and S.E. Karademir, Novel Total Antioxidant Capacity Index for Dietary Polyphenols and Vitamins C and E, Using Their Cupric Ion Reducing Capability in the Presence of Neocuproine: CUPRAC Method, Journal of Agricultural and Food Chemistry, 52(26), 2004, 7970-7981.

[24] O Benavente-Garcia, J. Castillo, F.R. Marin, A. Ortuno, and J.A. Del-Rio, Uses and properties of Citrus flavonoids, Journal of Agricultural and Food Chemistry, 45(12), 1997, 4505-4515.

[25] M Oktay, I. Gulcin, and O.I. Kufrevioglu, Determination of in vitro antioxidant activity of fennel (Foeniculum vulgare) seed extracts. LWT - Food Science and Technology, 36(2), 2003, 263-271.

[26] HE Miller, F. Rigelhof, L. Marquart, A. Prakash, and M. Kanter, Antioxidant Content of Whole Grain Breakfast Cereals, Fruits and Vegetables, Journal of the American College of Nutrition, 19(3), 2000, 312S-319S.

[27] GK Jayaprakasha, L.J. Rao, and K.K. Sakariah, Antioxidant activities of flavidin in different in vitro model systems, Bioorganic \& Medicinal Chemistry, 12(19), 2004, 5141-5146.

[28] GC Yen, and H.Y. Chen, Antioxidant Activity of Various Tea Extracts in Relation to Their Antimutagenicity, Journal of Agricultural and Food Chemistry, 43(1), 1995, 27-32. 


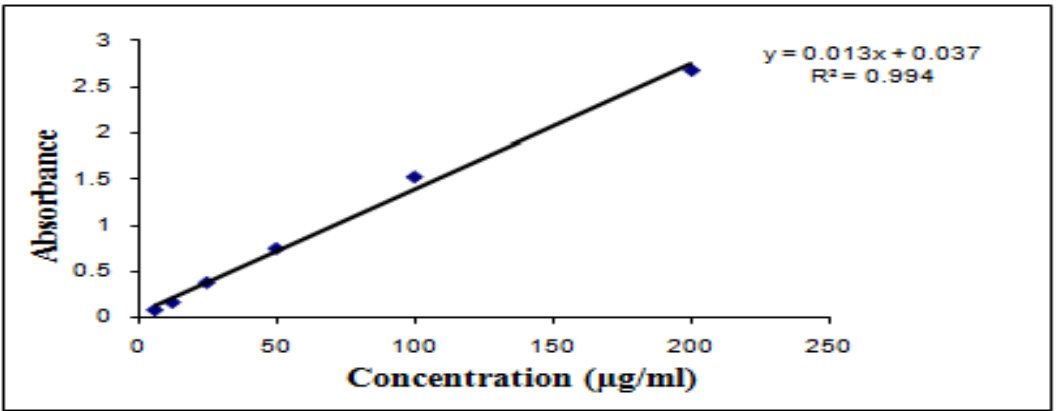

Fig. 1: Calibration curve of Gallic Acid

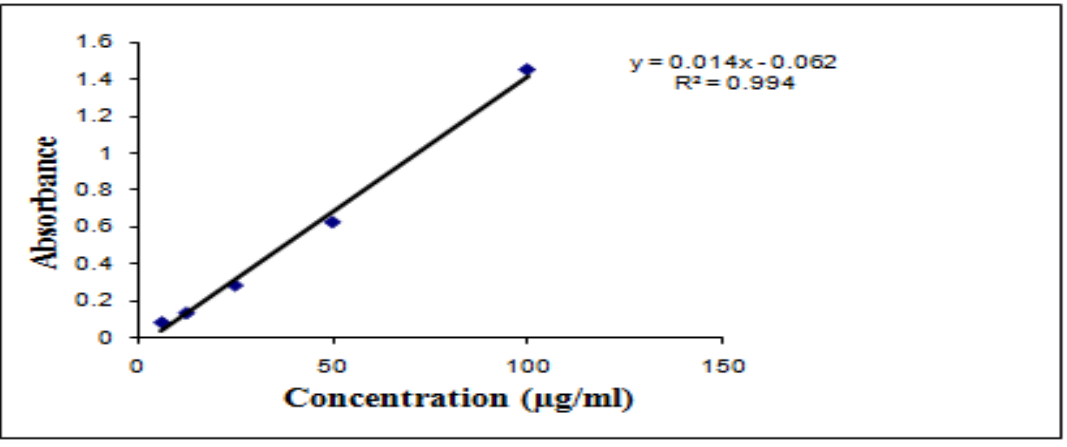

Fig. 2: Calibration curve of Quercetin

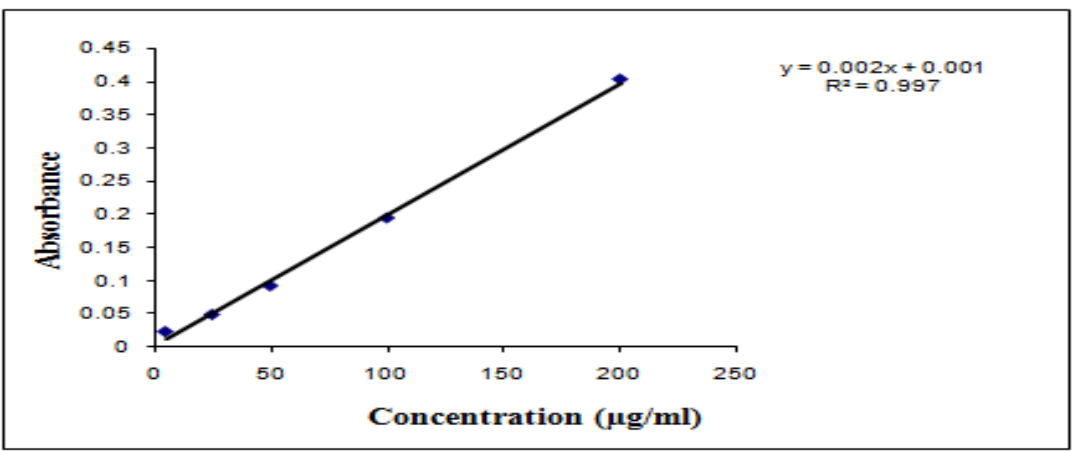

Fig. 3: Calibration curve of ascorbic acid

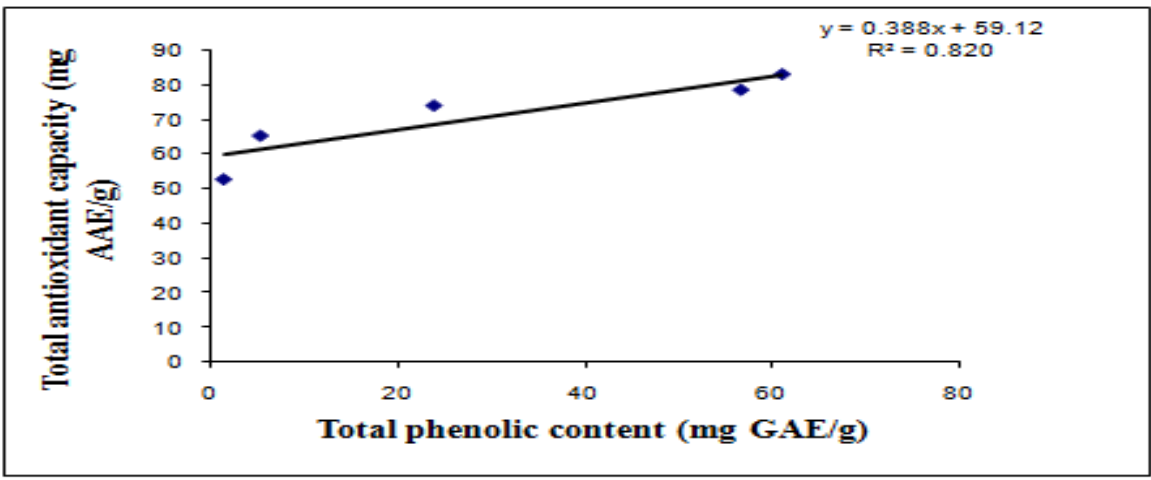

Fig. 4: Correlation between the total antioxidant capacity and the total phenolics contents of Withania somnifera extracts 


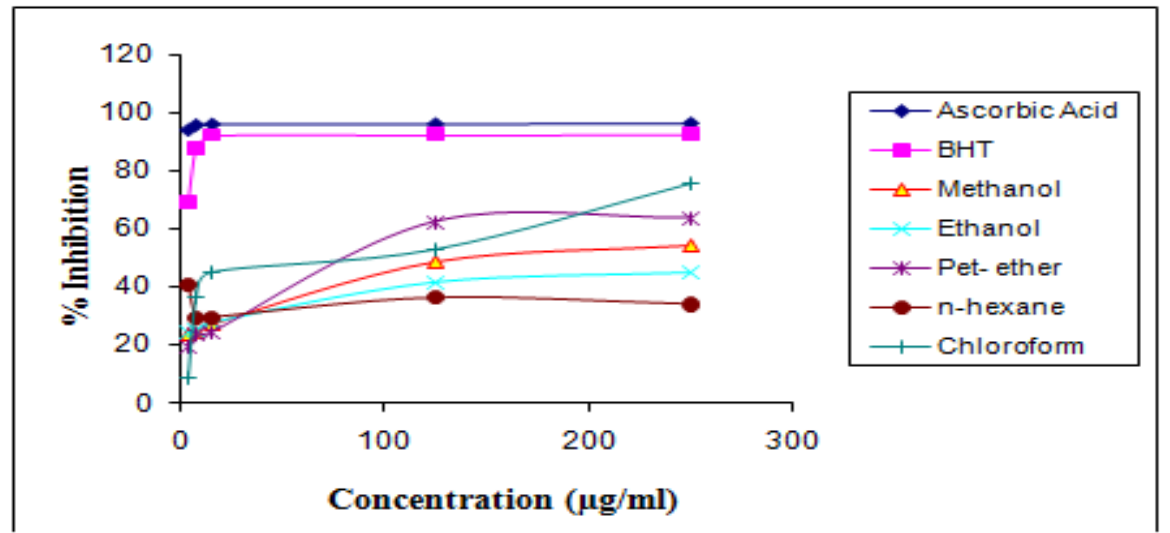

Fig. 5: Comparative DPPH radical scavenging activity of Withania somnifera root extract, ascorbic acid and butylated hydroxy toluene (BHT)

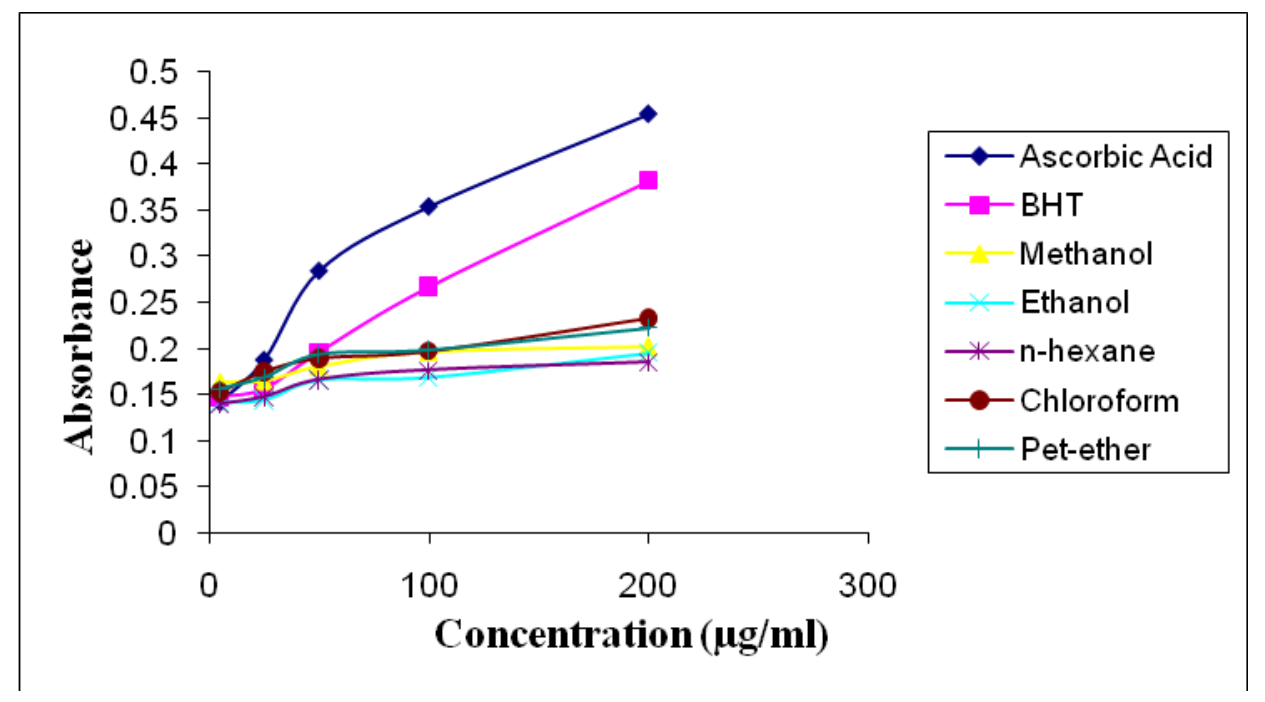

Fig. 6: Comparative reducing power capacity of Withania somnifera root extract, Ascorbic acid and butylated hydroxy toluene (BHT)

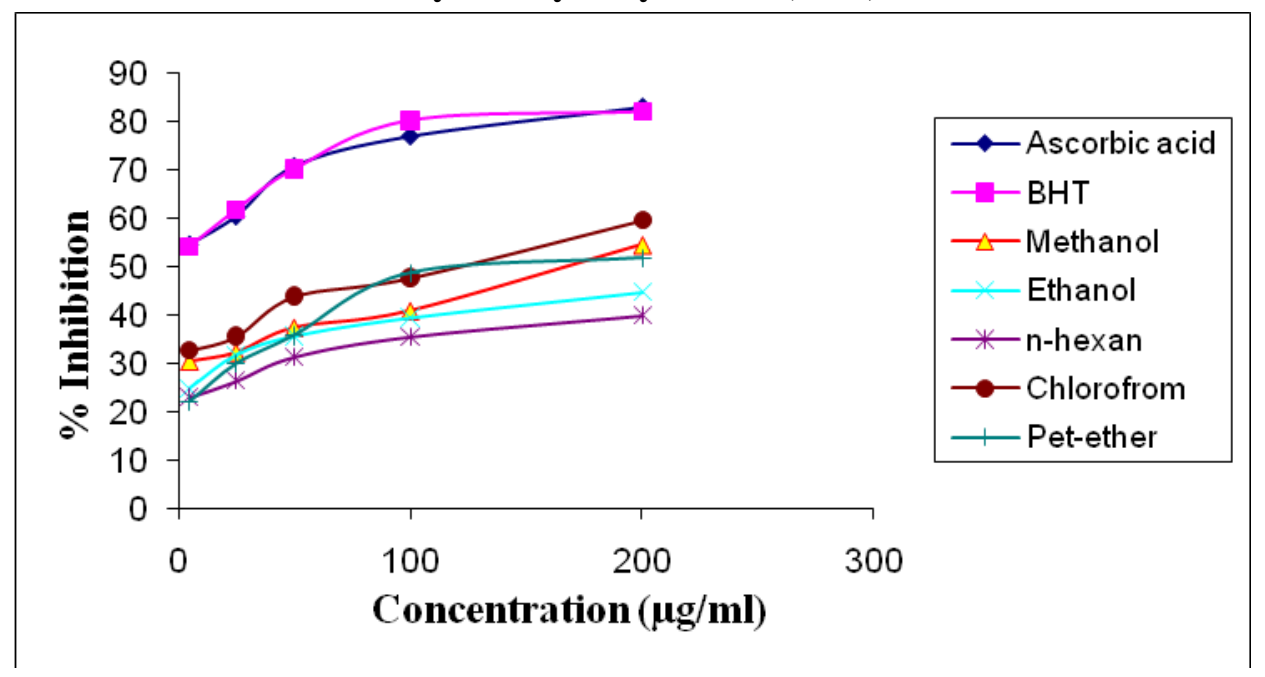

Fig. 7: Comparative $\mathrm{H}_{2} \mathrm{O}_{2}$ scavenging activity of Withania somnifera root extract, ascorbic acid and butylated hydroxy toluene (BHT) 


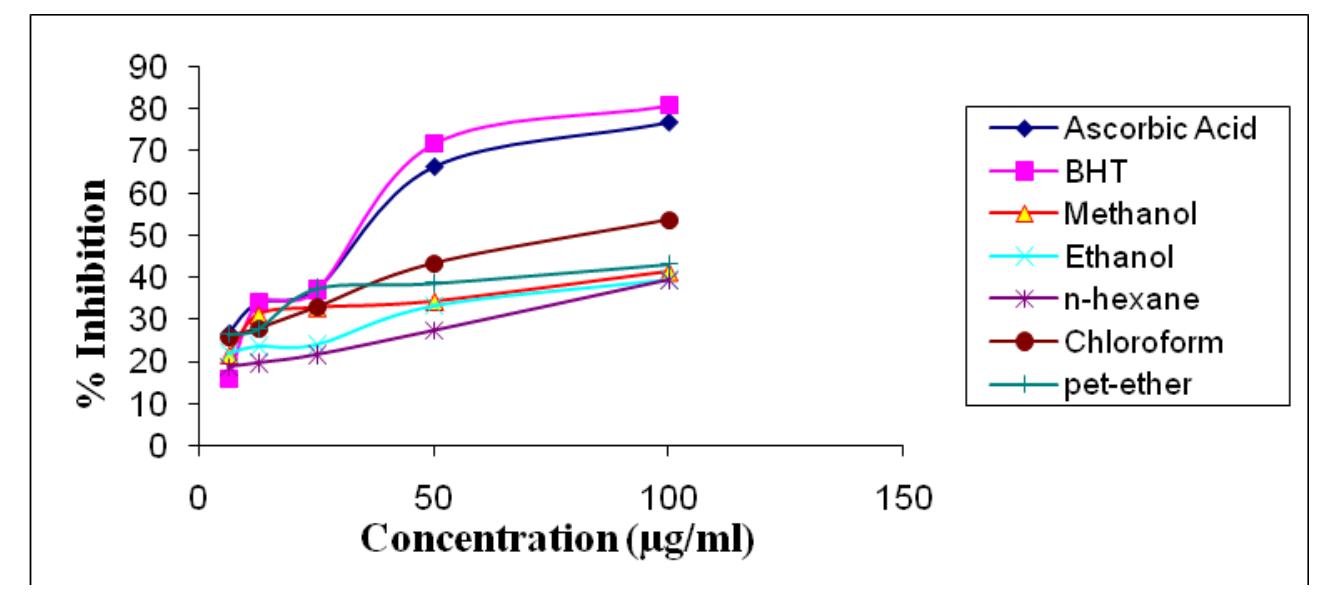

Fig. 8: Comparative nitric oxide scavenging activity of Withania somnifera root extract, ascorbic acid and butylated hydroxy toluene (BHT)

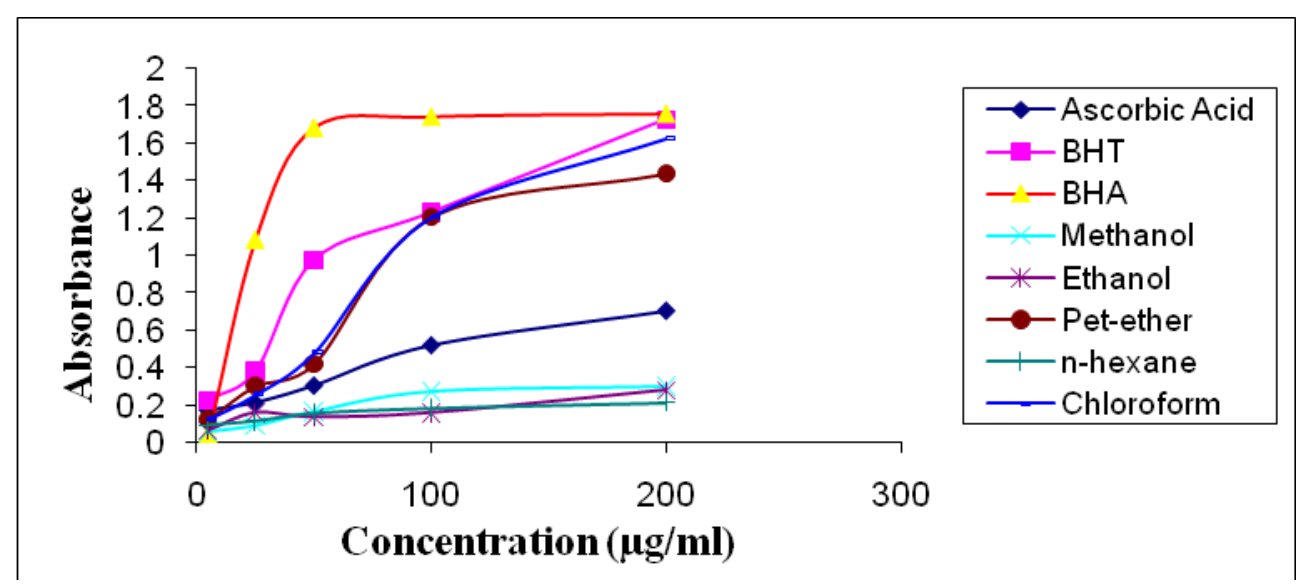

Fig. 9: Comparative cupric reducing antioxidant capacity of Withania somnifera root extract, ascorbic acid, butylated hydroxy toluene (BHT) and butylated hydroxy anisole (BHA).

Table 1: Total phenol contents of the different extracts of Withania somnifera

\begin{tabular}{lc}
\hline Extract & Total Phenol Contents ( $\mathbf{~ m g / g m , ~ G a l l i c ~ A c i d ~ E q u i v a l e n t ) ~}$ \\
\hline Methanol & $23.860 \pm 0.636$ \\
Ethanol & $5.355 \pm 0.561$ \\
Petroleum ether & $56.580 \pm 0.636$ \\
n-hexane & $1.433 \pm 0.972$ \\
Chloroform & $60.992 \pm 0.367$ \\
\hline
\end{tabular}

Values are the mean of duplicate experiments and represented as mean $\pm \mathrm{SD}$

Table 2: Total flavonoid contents of the different extracts of Withania somnifera

Extract $\quad$ Total Flavonoid Contents ( mg/gm, Quercetin Equivalent)

\begin{tabular}{lc}
\hline Methanol & $88.761 \pm 1.032$ \\
Ethanol & $66.013 \pm 0.585$ \\
n-hexane & $44.954 \pm 0.780$ \\
Chloroform & $122.094 \pm 1.351$ \\
Petroleum ether & $92.139 \pm 0.195$
\end{tabular}

Values are the mean of duplicate experiments and represented as mean $\pm \mathrm{SD}$ 
Table 3: Total antioxidant capacity of the different extracts of Withania somnifera

\begin{tabular}{lc}
\hline Extract & Total Antioxidant Capacity ( mg/gm, Ascorbic Acid Equivalent) \\
\hline Methanol & $73.925 \pm 20.254$ \\
Ethanol & $65.225 \pm 8.906$ \\
n-hexane & $52.675 \pm 17.690$ \\
Chloroform & $82.925 \pm 28.914$ \\
Petroleum ether & $78.425 \pm 20.544$ \\
\end{tabular}

Values are the mean of duplicate experiments and represented as mean $\pm \mathrm{SD}$

Table 4: $\mathrm{IC}_{50}$ values of different extracts of Withania somnifera in DPPH scavenging assay

\begin{tabular}{lc}
\hline Extracts/standard & IC $_{\mathbf{5 0}} \boldsymbol{\mu g} / \mathbf{m l}$ \\
\hline Methanol & 267.818 \\
Ethanol & 529.484 \\
Pet-ether & 144.998 \\
n-hexane & 1236.400 \\
Chloroform & 87.414 \\
Ascorbic acid & 5.698 \\
Butylated hydroxy toluene (BHT) & 8.816
\end{tabular}

Table 5: $\mathrm{IC}_{50}$ values of different extracts of Withania somnifera in $\mathrm{H}_{2} \mathrm{O}_{2}$ scavenging assay

\begin{tabular}{lc}
\hline Extracts/standard & $\mathbf{I C}_{\mathbf{5 0}} \boldsymbol{\mu g} / \mathbf{m l}$ \\
\hline Methanol & 172.661 \\
Ethanol & 327.505 \\
Pet-ether & 162.643 \\
n-hexane & 753.198 \\
Chloroform & 89.188 \\
Ascorbic acid & 7.529 \\
Butylated hydroxy toluene (BHT) & 6.387 \\
& \\
\hline
\end{tabular}

Table 6: $\mathrm{IC}_{50}$ values of the different extracts of Withania somnifera root in nitric oxide scavenging assay

\begin{tabular}{lc}
\hline Extracts/standard & $\mathbf{I C}_{\mathbf{5 0}} \boldsymbol{\mu g} / \mathbf{m l}$ \\
\hline Methanol & 449.004 \\
Ethanol & 718.879 \\
Pet-ether & 288.729 \\
n-hexane & 847.026 \\
Chloroform & 92.207 \\
Ascorbic acid & 27.685 \\
Butylated hydroxy toluene (BHT) & 27.294 \\
\end{tabular}

